\title{
NSC23766, a Known Inhibitor of Tiam1- Rac1 Signaling Module, Prevents the Onset of Type 1 Diabetes in the NOD Mouse Model
}

\author{
Rajakrishnan Veluthakal ${ }^{a}$ Vaibhav Sidaralab Anjaneyulu Kowluru ${ }^{b}$ \\ aDepartment of Molecular and Cellular Endocrinology, Diabetes and Metabolic Research Institute, City \\ of Hope/BRI, Duarte, bJohn D. Dingell VA Medical Center, and Department of Pharmaceutical Sciences, \\ Eugene Applebaum College of Pharmacy and Health Sciences, Wayne State University, Detroit, USA
}

\section{Key Words}

Nox2 • Rac1 • NOD mice $•$ Pancreatic islet $•$ ER stress $•$ Diabetes

\begin{abstract}
Background/Aims: Type 1 diabetes (T1D) is characterized by absolute insulin deficiency due to destruction of pancreatic $\beta$-cells by cytokines (e.g., interleukin-1 $\beta$; IL-1 $\beta$ ) released by invading immune cells. The mechanisms by which these cytokines induce $\beta$-cell dysfunction remain poorly understood. Recent evidence suggests that excessive generation of reactive oxygen species (ROS) by the phagocyte-like NADPH oxidase2 (Nox2), along with significantly low levels of antioxidants in $\beta$-cells, drive them toward oxidative damage. Rac1, a small G-protein, is one of the members of Nox2 holoenzyme. We recently reported that NSC23766, a known inhibitor of Rac1, significantly attenuated cytokine-induced Nox2 activation and ROS generation in pancreatic islet $\beta$-cells in vitro. Herein, we determined the effects of NSC23766 $(2.5 \mathrm{mg} / \mathrm{kg} /$ day, i.p/daily) on the development of diabetes in the NOD mouse, a model for T1D. Methods: Two groups of experimental animals (Balb/c and NOD mice) received NSC23766, while the two control groups received equal volume of saline. Body weights and blood glucose were measured every week for 34 weeks. Rac1 activation in pancreatic islets was measured by GLISA activation assay. Racl and CHOP expression was determined by Western Blotting. Results: Our findings indicate that administration of NSC23766 significantly prevented the development of spontaneous diabetes in the NOD mice. Furthermore, NSC23766 markedly suppressed Rac1 expression and activity and the endoplasmic reticulum stress (CHOP expression) in NOD islets. Conclusions: Our findings provide the first evidence implicating the role of Tiam1-Rac1-Nox2 signaling pathway in the onset of spontaneous diabetes in the NOD mouse model.
\end{abstract}

\section{Introduction}

Type-1 diabetes (T1D) is characterized by an absolute deficiency of insulin arising from progressive autoimmune destruction of pancreatic $\beta$-cells $[1,2]$. It is well established that during the progression of the disease, pro-inflammatory cytokines (IL- $1 \beta$, TNF- $\alpha$, and 


\section{Cellular Physiology Cell Physiol Biochem 2016;39:760-767 \\ \begin{tabular}{l|l|l} 
DOI: 10.1159/000445666 & $\begin{array}{l}\text { O 2016 The Author(s). Published by S. Karger AG, Basel } \\
\text { wwww.karger.com/cpb }\end{array}$
\end{tabular} \\ Veluthakal et al.: Rac1-Tiam1 Axis in the Onset of Diabetes in the NOD Mouse Model}

IFN- $\gamma$ ), are released into pancreatic islets by infiltrated, activated $\mathrm{T}$ cells and macrophages [3-8]. However, the exact cellular and molecular mechanisms by which cytokines induce $\beta$-cell demise remain partially understood [4-7]. Even though cytokines have been shown to modulate several signaling pathways, apoptosis is considered as the primary mode of cell death in human and mouse models [8].

A growing body of evidence supports the hypothesis that oxidative stress from reactive oxygen species (ROS), and nitric oxide (NO) contributes to the damage in mitochondrial membrane, eventually causing defects in the membrane potential. In contrast with most other mammalian cell types, $\beta$-cells comprise relatively lower levels of redox-regulating enzymes, making them more vulnerable to oxidative damage $[9,10]$. Recently, members of the NADPH oxidase (Nox) family (e.g., Nox1 and Nox2) have emerged as one of the sources of pathological oxidative stress in pancreatic islets under the duress of exposure to pro-inflammatory cytokines [11-14]. Under basal conditions, the phagocyte-like NADPH oxidase (Nox2) holoenzyme is inactive as its individual subunits are distributed in the soluble and membranous compartments. The membrane-bound catalytic core consists of flavocytochrome $b_{558}$ components $\mathrm{p} 22^{\text {phox }}$ and gp91 ${ }^{\text {phox }}$ and small G-protein Rap1. The regulatory core consisting of $\mathrm{p} 47^{\text {phox }}, \mathrm{p} 67^{\text {phox }}$, and $\mathrm{p} 40^{\text {phox }}$ subunits and the small G-protein Rac1 reside in the cytosol. Upon stimulation, the cytosolic components are translocated to the membrane for holoenzyme assembly and activation of the enzyme $[15,16]$. Our recent findings have also demonstrated that functional activation of Rac1 (i.e., GTP-Rac1) is vital for the NADPH holoenzyme assembly $[12,13]$.

Several recent studies have demonstrated localization and functional activation of the phagocyte-like NADPH in clonal $\beta$-cells, normal rat islets, and human islets under the duress of various stimuli, including elevated levels of glucose, saturated fatty acids, and pro-inflammatory cytokines [12, 17-22]. Furthermore, pharmacological inhibition of Nox2 by diphenyleneiodonium chloride (DPI) or anti-sense oligonucleotides for $\mathrm{p} 47^{\text {phox }}$ markedly attenuate glucose-induced ROS production and oxidative stress, suggesting critical involvement of Nox2 in the metabolic dysfunction induced by long-term exposure to elevated glucose [23]. These data implicated a significant contributory role for NADPH oxidase in the onset of metabolic dysfunction of the $\beta$-cell under conditions of oxidative stress $[24,25]$. Along these lines, in vitro studies (pharmacological and siRNA) from our laboratory have demonstrated key roles for pro-inflammatory cytokines in the induction of Tiam1-Rac1Nox2 pathway leading to mitochondrial dysfunction and caspase activation in pancreatic $\beta$-cells $[12,26]$. As a logical extension to these in vitro findings, we have undertaken the current investigation to validate our hypothesis that Tiam1-Rac1-Nox2 pathway contributes to cytokine-mediated islet dysfunction in the NOD mouse, a well-established model for T1D. Our findings demonstrate that NSC23766, a known inhibitor of Tiam1-Rac1 signaling pathway inhibits spontaneous diabetes in this mouse model.

\section{Materials and Methods}

\section{Materials}

NSC23766 was from Calbiochem (Minneapolis, MN). Rac1 activation G-LISA assay kit was from Cytoskeleton Inc. (Denver, CO). CHOP antiserum was from Cell Signaling Technology (Danvers, MA). Mouse monoclonal antibody directed against Rac1 was purchased from BD Bioscience (San Jose, CA). Beta-actin antibody was from Sigma Chemical Company (St. Louis. MO). Blood glucometer and glucose strips were from Abbott Diabetes Care (Alameda, CA).

\section{Experimental Animals}

All animal protocols were reviewed and approved by the Institutional Animal Care and Use Committees at Wayne State University and the John D. Dingell VA Medical Center. Balb/c control and NOD mice were purchased from Jackson laboratories (Bar Harbor, Maine) The animals were purchased at 7 weeks of age and were divided into four groups ( $\mathrm{n}=8$ /group). At 8 weeks of age two groups of experimental animals 


\section{Cellular Physiology Cell Physiol Biochem 2016;39:760-767 \\ \begin{tabular}{l|l} 
DOI: 10.1159/000445666 & $\begin{array}{l}\text { O 2016 The Author(s). Published by S. Karger AG, Basel } \\
\text { wwww.karger.com/cpb }\end{array}$
\end{tabular} \\ Veluthakal et al.: Rac1-Tiam1 Axis in the Onset of Diabetes in the NOD Mouse Model}

(Balb/c and NOD) received NSC23766 (2.5mg/kg/day, i.p./daily) and other two groups, which served as control Balb/c and NOD mice and received equal volume of saline. The body weights and blood glucose were monitored every week for 34 weeks.

\section{Blood glucose monitoring}

Blood glucose was monitored weekly by tail vein nick using Freestyle Lite blood glucose meter (Abbott Diabetes Care, Alameda, CA). Mice presenting with a blood glucose concentration of $250 \mathrm{mg} / \mathrm{dl}$ or higher, for two consecutive weeks were considered to be diabetic.

Islet isolation

Islets from all the experimental groups were isolated according to collagenase digestion method as we described previously $[17,19]$.

Rac1 activation assay

Rac1 activation from islets was quantified using a G-LISA assay kit as described in $[27,28]$.

Western blotting

Islet cell lysate proteins (20 - $30 \mu \mathrm{g} / \mathrm{lane}$ ) were separated by SDS-PAGE and transferred to a nitrocellulose membrane. The membrane was then probed using Rac1 and CHOP antibodies and further incubated with corresponding secondary antibodies. The same blots were stripped and used to probe for $\beta$-actin to ensure equal loading and transfer of proteins.

Statistical analysis of experimental data

The statistical significance of the differences between the experimental conditions was determined by ANOVA. $P$ values $<0.05$ were considered significant.

\section{Results}

Previous investigations from multiple laboratories including our own have implicated Tiam1-Rac1 signaling module in the activation of Nox2 and associated increase in ROS generation under conditions of metabolic stress [20, 28, 29]. Specifically, studies from our laboratory have reported significant attenuation of cytokine-induced metabolic dysregulation of $\beta$-cell following inhibition of Tiam1-Rac1 signaling pathway by NSC23766 [12]. Therefore, we undertook the current investigation to assess the role(s) of Tiam1-Rac1 pathway in the onset of spontaneous diabetes in NOD mouse, a model for T1D.

NSC23766 treatment elicited no significant effects on the growth (body weights) of either Balb/c or NOD mice

Data depicted in Fig. 1 (Panel A) demonstrate no significant effects of NSC23766 on the body weights of either the control Balb/c mice or the NOD mice. Their body weights at the beginning of the study ( 8 wks.) represented $18.75 \pm 0.13$ grams and $19.68 \pm 0.19$ grams for Balb/c mice and NOD mice, respectively. At the end of the study ( 32 wks.) the corresponding body weights of control group were $25.85 \pm 0.95$ grams (vehicle-treated) and $22.66 \pm 0.52$ grams (NSC23766-treated). The body weights of NOD mice represented $24.13 \pm 2.09$ grams (vehicle-treated) vs. $24.86 \pm 1.32$ grams (NSC23766-treated). Together, these data suggest no clear effects of NSC23766 on body weights of the animal throughout the course of the study.

NSC23766 treatment significantly attenuated the onset of spontaneous diabetes in NOD mice

Data shown in Fig. 1 (Panel B) demonstrate a marked reduction in the development of hyperglycemia in NOD mice treated with NSC23766. At the beginning of the study ( 8 wks.), the blood glucose values corresponded to $127 \pm 1.50 \mathrm{mg} / \mathrm{dl}$ and $109 \pm 11.44 \mathrm{mg} / \mathrm{dl}$ for Balb/c 
Fig. 1. NSC23766 prevents the incidence of diabetes in NOD mice. (Panel A) NOD mice and Balb/c control mice were divided into two groups each. NSC23766 administration $(2.5 \mathrm{mg} / \mathrm{kg} /$ day) was started at 8 weeks of age and the corresponding control group received saline. Body weights were measured every week. Data are mean from 10-14 mice/group. (Panel B) NOD mice and Balb/c control mice were divided into two groups each. NSC23766 administration $(2.5 \mathrm{mg} /$ $\mathrm{kg} /$ day) was started at 8 weeks of age and the corresponding control group received saline. Blood glucose was monitored every week. Data are mean from 10-14 mice/ group. * represents $\mathrm{p}<0.001$ vs Balb/c and ** represents $\mathrm{p}<0.001$ vs NOD control mice.

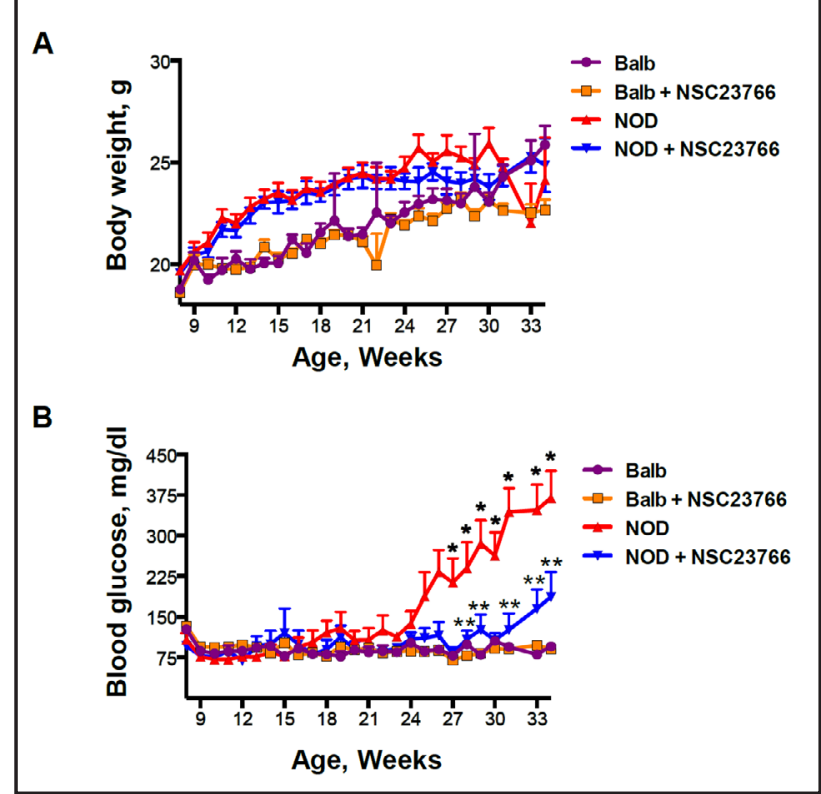

Fig. 2. NSC23766 suppresses the expression of Rac1 and CHOP in NOD mouse islets. NOD mice and Balb/c control mice were divided into two groups each. NSC23766 administration was started at 8 weeks of age $(2.5 \mathrm{mg} /$ $\mathrm{kg} /$ day) daily and the corresponding control group received saline. After the end of week 32 for first study (Panel A) and week 34 for the second study (Panel B),

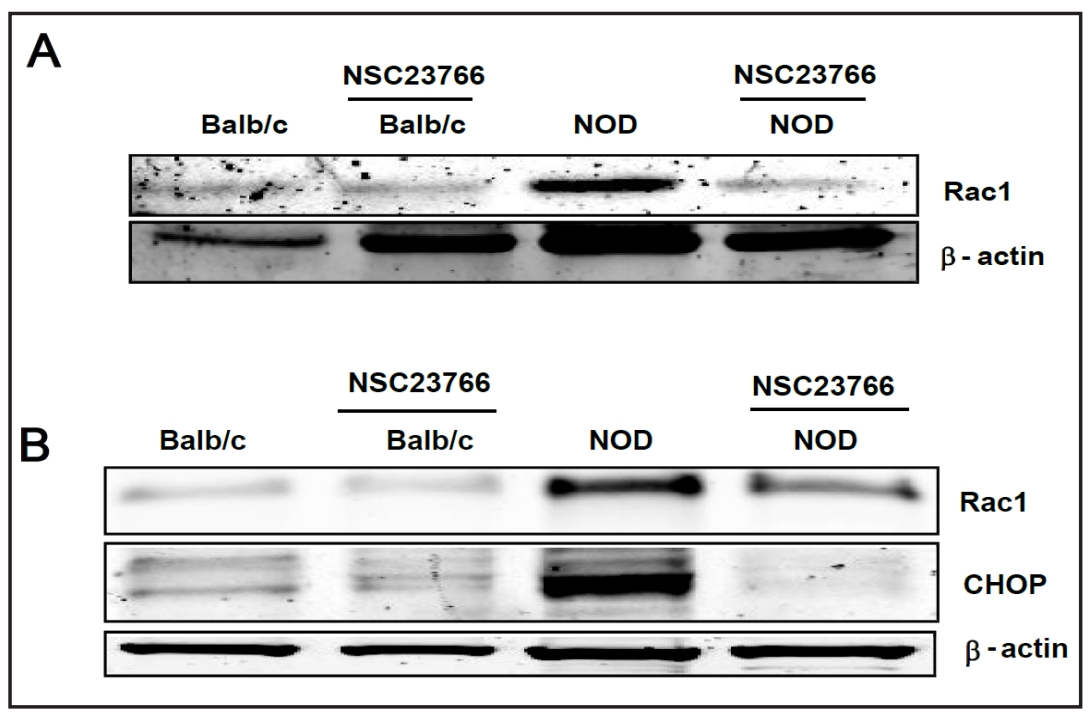
islets were isolated by collagenase digestion method and expression of Rac1 and CHOP was determined by Western blotting. Protein loading in each lane was quantified by stripping the same blot and re probing with $\beta$-actin. A representative blot from two independent studies is shown here.

and NOD mice, respectively. At 32 wks., the blood glucose values remained unchanged in Balb/c mice treated with either vehicle $(96 \pm 6 \mathrm{mg} / \mathrm{dl})$ or NSC23766 (91 $\pm 5 \mathrm{mg} / \mathrm{dl})$. As expected, blood glucose levels were significantly higher in NOD mice at 32 wks. (370 \pm 50 $\mathrm{mg} / \mathrm{dl}$ ). NSC23766 treatment of NOD mice significantly reduced their blood glucose levels (187 $\pm 46 \mathrm{mg} / \mathrm{dl})$. Together, data in Fig. 1 (Panels B) indicate a marked reduction in the onset of spontaneous hyperglycemia in NOD mice following treatment with NSC23766, a known inhibitor of Tiam1-Rac1 signaling pathway.

Administration of NSC23766 markedly attenuates increased expression of Rac1 and CHOP, a marker for ER-stress, in islets from NOD mice

In the next of studies, we quantified expression of Rac1 and CHOP, an ER-stress marker, in islets derived from Balb/c mice and NOD mice treated without or with NSC23766 (32 wks.). Data shown in Fig. 2 indicate a significant increase in the expression of Rac1 in islets KARGER 


\section{Cellular Physiology and Biochemistry

Fig. 3. NSC23766 prevents Rac1 activation in NOD mouse islets. NOD mice and Balb/c control mice were divided into two groups each. NSC23766 administration was started at 8 weeks of age $(2.5 \mathrm{mg} /$ $\mathrm{kg} /$ day) daily and the corresponding control group received saline. After the end of week 34, islets were isolated by collagenase digestion method and activation of Rac1 was quantified by the G-LISA method. Data are expressed as fold change \pm SEM. * represents $\mathrm{p}<0.05 v s$. Balb/c and ${ }^{* *}$ represents $\mathrm{p}<0.05$ vs. NOD, $\mathrm{N}=3$.

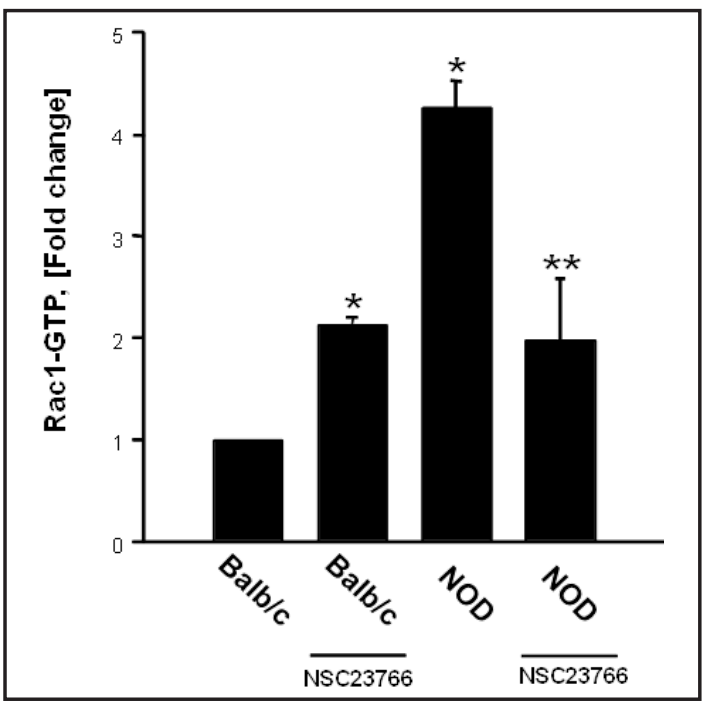

derived from NOD mice (Panel A and B), which as suppressed significantly in islets from NOD mice treated with NSC23766. Further, we noticed a marked increase in the expression of CHOP in NOD mouse islets (Fig. 2; Panel B), which was inhibited completely in islets from NOD mice treated with NSC23766. Together, these data indicate that activation of Nox2 may be upstream to the induction of CHOP expression (and ER stress).

Treatment of NOD mice with NSC23766 significantly reduces Rac1 activation

In the last set of studies, we quantified Rac1 activation (G-LISA; Methods for additional details) in islets derived from Balb/c or NOD mice treated with vehicle or NSC23766. Data in Fig. 3 indicate a paradoxical increase ( $\sim 2$ fold) in Rac1 activation in Balb/c mice treated with NSC23766. We also noticed nearly $\sim 4.5$ fold stimulation in Rac1 activation in islets from NOD mice, which was inhibited significantly following treatment of NOD mice with NSC23766. Together, these data of significant suppression of Rac1 activation in NOD mice by NSC23766 suggest a critical regulatory role for Tiam1 in the induction of Rac1 activation (Fig. 3) and induction of hyperglycemia in the NOD mouse model.

\section{Discussion}

Emerging evidence from multiple laboratories including our own implicates regulatory roles for Nox2 in the metabolic dysfunction under the duress of glucolipotoxicity and cytokines. The overall goal of this study was to further understand the role of Tiam1-Rac1Nox2 in the induction of islet dysfunction in the NOD mouse model. Our studies yielded some novel clues suggesting that: (i) expression of Rac1 and CHOP are increased in the NOD mouse model (at 32 wks.) and NSC23766 significantly attenuated expression of both Rac1 and CHOP; (ii) Rac1 is also activated in NOD mouse islets which was significantly inhibited by NSC23766; and (iii) NSC23766 administration to NOD mouse significantly prevented the spontaneous development of hyperglycemia in this model. Based on these findings we suggest novel roles for Tiam1-Rac1-Nox2 in the induction of T1DM in the NOD mouse model.

Several recent studies have explored potential utility of inhibitors of specific guanine nucleotide exchange factors (GEFs) for Rac1 as modulators of its activation under the duress of glucolipotoxicity, pro-inflammatory cytokine exposure and diabetes $[12,18,19$, 30]. It is well established that activation of Rac1 is mediated by a variety of GEFs including Tiam1, Vav2 and Trio [16, 27, 31, 32]. In 2004, Gao and associates discovered NSC23766, a small molecule compound, that specifically inhibited Tiam 1 or Trio-induced activation of Rac1 [33]. Activation of other small G-proteins (Cdc42 and Rho) remained unaffected by NSC23766. Furthermore, NSC23766 significantly attenuated Rac1-mediated proliferation, 


\section{Cellular Physiology Cell Physiol Biochem 2016;39:760-767 \\ \begin{tabular}{c|c|c|c|} 
DOI: 10.1159/000445666 & $\begin{array}{l}\text { O 2016 The Author(s). Published by S. Karger AG, Basel } \\
\text { wwww.kargercom/cpb }\end{array}$
\end{tabular} \\ Veluthakal et al.: Rac1-Tiam1 Axis in the Onset of Diabetes in the NOD Mouse Model}

anchorage-independent growth and invasion phenotypes in human prostate cancer PC-3 cells [33]. Since then, more than 200 studies (a recent Medline search) employed NSC23766 as inhibitor of Rac1 activation.

In the context of islet $\beta$-cell, we have utilized NSC23766 to further investigate regulatory roles of Tiam1-Rac1 signaling cascade in islet function. Compatible with original findings of Gao and coworkers [33], we observed that NSC23766 significantly inhibited only Rac1, but not Cdc42 or Rho activation [32]. Our in vitro [12] and in vivo (current study) observations clearly implicate regulatory roles for Rac1 in cytokine-induced islet dysfunction. We also identified Tiam 1 as one of the GEFs that is involved in cytokine-induced Rac1 activation since NSC23766, a known inhibitor of Tiam1, inhibited cytokine-induced Rac1 activation. In the current study, we observed that administration of NSC23766 $(2.5 \mathrm{mg} / \mathrm{kg} /$ day, i.p./daily) prevents the onset of spontaneous diabetes in the NOD mouse model. We recently used this dosage in mouse models to demonstrate regulatory roles of Tiam1-Rac1-Nox2 pathway in diabetic retinopathy $[28,34]$. Studies by Shibata et al. have employed NSC23766 at a dose of $10 \mathrm{mg} / \mathrm{kg} /$ day which is four times the dose we have used, and observed reduced Rac1 activity in the kidney without apparent evidence of organ toxicity in mice [35]. In summary, these findings in the NOD mouse model confirm our in vitro observations suggesting that cytokine-induced islet dysfunction may be mediated via the activation of Tiam1-Rac1-Nox2 signaling module.

Interestingly, we observed increased Rac1 activation in Balb/c mice treated with NSC23766. These data suggest potential involvement of other GEFs in the activation of Rac1 in this model system. Along these lines, recent data from our laboratory have demonstrated that two GEFS, namely Tiam1 and Vav2, are involved in the activation of Rac1 to facilitate glucose-stimulated insulin secretion [GSIS] since simultaneous inhibition of Tiam1-Rac1 [NSC23766] and Vav2-Rac1 [Ehop-016] pathways yielded much greater inhibition of GSIS, compared to inhibition of either of these pathways alone [27]. Therefore, the increased Rac1 activation in control Balb/c mice might be due to compensatory mechanism[s] by which Vav2 might be activating Rac1. Furthermore, based on our previous findings, it appears that post-translational geranylgeranylation and palmitoylation of Rac1 are also critical for regulatory effects of Rac1 since we reported significant inhibitory effects of inhibitors of geranylgeranylation (GGTI-2147) and palmitoylation (2-bromopalmitate) attenuated cytokine-mediated effects on the islet $\beta$-cell $[12,26]$. One potential caveat in these conclusions is that both GGTI-2147 and 2-bromopalmitate would impede geranylgeranylation and palmitoylation of other candidate proteins. Therefore, additional studies are needed to further validate the above model.

Our data also suggest significant increase in CHOP expression (i.e., ER-stress) in NOD mouse islets, which was inhibited significantly in islets derived from NSC23766-treated NOD mice suggesting that Tiam1-Rac1 activation may be upstream to CHOP expression and induction of ER stress. Additional studies are needed to further validate this formulation. Our findings in NOD mice are compatible with observations of Tersey and associates demonstrating that ER stress precedes the onset of T1D in the NOD mouse. They were able to substantiate this hypothesis both in in vitro and in vivo model systems [36].

Lastly, it should be pointed out that while our previous and current findings are suggestive of key regulatory roles for Nox2 in cytokine-mediated islet dysfunction, it is likely that other Noxs could contribute to the pathogenesis of islet defects. Indeed, recent studies from Taylor-Fishwick's group have demonstrated key modulatory roles for Nox1 in cytokine-mediated dysfunction of the islet $\beta$-cell [11]. ML171, a selective inhibitor of Nox1 significantly reduced cytokine-induced ROS generation and caspase activation in clonal $\beta$-cells and mouse islets. It would be worthwhile to determine the cytoprotective effects of NSC23766 and ML171 (in combination) to further assess the validity of the hypothesis that Nox (Nox1 and 2) derived ROS generation and oxidative stress are causal for $\beta$-cell damage under the duress of cytokines. In conclusion, we provide the first pharmacological evidence to implicate Tiam1-Rac1-Nox2 signaling pathway in the onset of T1D in the NOD mouse model. 


\section{Cellular Physiology Cell Physiol Biochem 2016;39:760-767 \begin{tabular}{l|l} 
DOI: 10.1159/000445666 & $\begin{array}{l}\text { O 2016 The Author(s). Published by S. Karger AG, Basel } \\
\text { wwww.karger.com/cpb }\end{array}$
\end{tabular} \\ Veluthakal et al.: Rac1-Tiam1 Axis in the Onset of Diabetes in the NOD Mouse Model}

\section{Abbreviations}

NOD mice (Non obese diabetic mice); T1D (Type 1 diabetes); Rac1 (Ras-related C3 botulinum toxin substrate 1); Tiam1 (T-lymphocyte invasive and metastasis protein 1); ROS (Reactive oxygen species); Nox2 (NADPH oxidase2); CHOP (C/EBP homologous protein); IL$1 \beta$ (Interleukin-1 $\beta$ ); TNF- $\alpha$ (Tumor necrosis factor- $\alpha$ ); IFN- $\gamma$ (Interferon- $\gamma$ ); GEF (Guanine nucleotide exchange factor); ER Stress (Endoplasmic reticulum stress).

\section{Acknowledgements}

This work was supported by grants to A.K from the Department of VA Medical Research Service, the National Institutes of Health, and the Juvenile Diabetes Research Foundation. A.K is the recipient of a Senior Research Career Scientist Award from the Department of VA. VS is supported by a cGRA from Wayne State University. The authors thank Khadija Syeda for help in these studies.

\section{Disclosure Statement}

The authors report no conflicts of interest.

\section{References}

1 Cabrera SM, Rigby MR, Mirmira RG: Targeting regulatory T cells in the treatment of type 1 diabetes mellitus. Curr Mol Med 2012;12:1261-1272.

2 Bluestone JA, Herold K, Eisenbarth G: Genetics, pathogenesis and clinical interventions in type 1 diabetes. Nature 2010;464:1293-1300.

3 Mandrup-Poulsen T: Beta-cell apoptosis: Stimuli and signaling. Diabetes 2001;50:S58-63.

4 Cetkovic-Cvrlje M, Eizirik DL: TNF-alpha and ifn-gamma potentiate the deleterious effects of il-1 beta on mouse pancreatic islets mainly via generation of nitric oxide. Cytokine 1994;6:399-406.

5 Veluthakal R, Chvyrkova I, Tannous M, McDonald P, Amin R, Hadden T, Thurmond DC, Quon MJ, Kowluru A: Essential role for membrane lipid rafts in interleukin-1beta-induced nitric oxide release from insulinsecreting cells: Potential regulation by caveolin-1+. Diabetes 2005;54:2576-2585.

6 Padgett LE, Broniowska KA, Hansen PA, Corbett JA, Tse HM: The role of reactive oxygen species and proinflammatory cytokines in type 1 diabetes pathogenesis. Ann N Y Acad Sci 2013;1281:16-35.

7 Cnop M, Welsh N, Jonas JC, Jorns A, Lenzen S, Eizirik DL: Mechanisms of pancreatic beta-cell death in type 1 and type 2 diabetes: Many differences, few similarities. Diabetes 2005;54:S97-107.

8 O'Brien BA, Harmon BV, Cameron DP, Allan DJ: Apoptosis is the mode of beta-cell death responsible for the development of IDDM in the nonobese diabetic (nod) mouse. Diabetes 1997;46:750-757.

9 Lenzen S, Drinkgern J, Tiedge M: Low antioxidant enzyme gene expression in pancreatic islets compared with various other mouse tissues. Free Radic Biol Med 1996;20:463-466.

10 Grankvist K, Marklund SL, Taljedal IB: CuZn-superoxide dismutase, mn-superoxide dismutase, catalase and glutathione peroxidase in pancreatic islets and other tissues in the mouse. Biochem J 1981;199:393-398.

11 Weaver JR, Grzesik W, Taylor-Fishwick DA: Inhibition of NADPH oxidase-1 preserves beta cell function. Diabetologia 2015;58:113-121.

12 Subasinghe W, Syed I, Kowluru A: Phagocyte-like NADPH oxidase promotes cytokine-induced mitochondrial dysfunction in pancreatic beta-cells: Evidence for regulation by Rac1. Am J Physiol Regul Integr Comp Physiol 2011;300:R12-20.

13 Jastroch M: Unraveling the molecular machinery that promotes pancreatic beta-cell dysfunction during oxidative stress: Focus on "Phagocyte-like NADPH oxidase promotes cytokine-induced mitochondrial dysfunction in pancreatic beta-cells: Evidence for regulation by Rac1". Am J Physiol Regul Integr Comp Physiol 2011;300:R9-11.

14 Padgett LE, Burg AR, Lei W, Tse HM: Loss of NADPH oxidase-derived superoxide skews macrophage phenotypes to delay type 1 diabetes. Diabetes 2015;64:937-946.

15 Pick E: Role of the Rho GTPase Rac in the activation of the phagocyte nadph oxidase: Outsourcing a key task. Small GTPases 2014;5:e27952. 


\section{Cellular Physiology Cell Physiol Biochem 2016;39:760-767

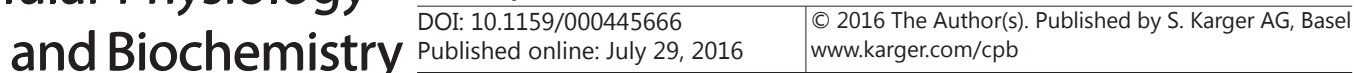 \\ Veluthakal et al.: Rac1-Tiam1 Axis in the Onset of Diabetes in the NOD Mouse Model}

16 Kowluru A: Small G proteins in islet beta-cell function. Endocr Rev 2010;31:52-78.

17 Syed I, Kyathanahalli CN, Jayaram B, Govind S, Rhodes CJ, Kowluru RA, Kowluru A: Increased phagocytelike NADPH oxidase and ROS generation in type 2 diabetic ZDF rat and human islets: Role of RAC1-JNK1/2 signaling pathway in mitochondrial dysregulation in the diabetic islet. Diabetes 2011;60:2843-2852.

18 Syed I, Jayaram B, Subasinghe W, Kowluru A: Tiam1/Rac1 signaling pathway mediates palmitate-induced, ceramide-sensitive generation of superoxides and lipid peroxides and the loss of mitochondrial membrane potential in pancreatic beta-cells. Biochem Pharmacol 2010;80:874-883.

19 Sidarala V, Veluthakal R, Syeda K, Vlaar C, Newsholme P, Kowluru A: Phagocyte-like NADPH oxidase (Nox2) promotes activation of p38MAPK in pancreatic beta-cells under glucotoxic conditions: Evidence for a requisite role of Ras-related C3 botulinum toxin substrate 1 (Rac1). Biochem Pharmacol 2015;95:301-310.

20 Kowluru A, Kowluru RA: Phagocyte-like NADPH oxidase [Nox2] in cellular dysfunction in models of glucolipotoxicity and diabetes. Biochem Pharmacol 2014;88:275-283.

21 Morgan D, Oliveira-Emilio HR, Keane D, Hirata AE, Santos da Rocha M, Bordin S, Curi R, Newsholme P, Carpinelli AR: Glucose, palmitate and pro-inflammatory cytokines modulate production and activity of a phagocyte-like NADPH oxidase in rat pancreatic islets and a clonal beta cell line. Diabetologia 2007;50:359369.

22 Mohammed AM, Kowluru A: Activation of apocynin-sensitive NADPH oxidase (Nox2) activity in INS-1 832/13 cells under glucotoxic conditions. Islets 2013;5:129-131.

23 Morgan D, Rebelato E, Abdulkader F, Graciano MF, Oliveira-Emilio HR, Hirata AE, Rocha MS, Bordin S, Curi R, Carpinelli AR: Association of NAD(P)H oxidase with glucose-induced insulin secretion by pancreatic beta-cells. Endocrinology 2009;150:2197-2201.

24 Oliveira HR, Verlengia R, Carvalho CR, Britto LR, Curi R, Carpinelli AR: Pancreatic beta-cells express phagocyte-like NAD(P)H oxidase. Diabetes 2003;52:1457-1463.

25 Uchizono Y, Takeya R, Iwase M, Sasaki N, Oku M, Imoto H, Iida M, Sumimoto H: Expression of isoforms of NADPH oxidase components in rat pancreatic islets. Life Sci 2006;80:133-139.

26 Mohammed AM, Syeda K, Hadden T, Kowluru A: Upregulation of phagocyte-like NADPH oxidase by cytokines in pancreatic beta-cells: Attenuation of oxidative and nitrosative stress by 2-bromopalmitate. Biochem Pharmacol 2013;85:109-114.

27 Veluthakal R, Tunduguru R, Arora DK, Sidarala V, Syeda K, Vlaar CP, Thurmond DC, Kowluru A: Vav2, a guanine nucleotide exchange factor for Rac1, regulates glucose-stimulated insulin secretion in pancreatic beta cells. Diabetologia 2015;58:2573-2581.

28 Kowluru RA, Kowluru A, Veluthakal R, Mohammad G, Syed I, Santos JM, Mishra M: Tiam1-Rac1 signalling axis-mediated activation of NADPH oxidase-2 initiates mitochondrial damage in the development of diabetic retinopathy. Diabetologia 2014;57:1047-1056.

29 Shen E, Li Y, Li Y, Shan L, Zhu H, Feng Q Arnold JM, Peng T: Rac1 is required for cardiomyocyte apoptosis during hyperglycemia. Diabetes 2009;58:2386-2395.

30 Kowluru A: Friendly, and not so friendly, roles of Rac1 in islet beta-cell function: Lessons learnt from pharmacological and molecular biological approaches. Biochem Pharmacol 2011;81:965-975.

31 Jayaram B, Syed I, Kyathanahalli CN, Rhodes CJ, Kowluru A: Arf nucleotide binding site opener [ARNO] promotes sequential activation of Arf6, Cdc42 and Rac1 and insulin secretion in INS 832/13 beta-cells and rat islets. Biochem Pharmacol 2011;81:1016-1027.

32 Veluthakal R, Madathilparambil SV, McDonald P, Olson LK, Kowluru A: Regulatory roles for Tiam1, a guanine nucleotide exchange factor for rac1, in glucose-stimulated insulin secretion in pancreatic betacells. Biochem Pharmacol 2009;77:101-113.

33 Gao Y, Dickerson JB, Guo F, Zheng J, Zheng Y: Rational design and characterization of a Rac GTPase-specific small molecule inhibitor. Proc Natl Acad Sci U S A 2004;101:7618-7623.

34 Veluthakal R, Kumar B, Mohammad G, Kowluru A, Kowluru RA: Tiam1-Rac1 Axis Promotes Activation of p38 MAP Kinase in the Development of Diabetic Retinopathy: Evidence for a Requisite Role for Protein Palmitoylation. Cell Physiol Biochem 2015;36:208-220.

35 Shibata S, Nagase M, Yoshida S, Kawarazaki W, Kurihara H, Tanaka H, Miyoshi J, Takai Y, Fujita T: Modification of mineralocorticoid receptor function by Rac1 GTPase: implication in proteinuric kidney disease. Nat Med 2008;14:1370-1376.

36 Tersey SA, Nishiki Y, Templin AT, Cabrera SM, Stull ND, Colvin SC, Evans-Molina C, Rickus JL, Maier B, Mirmira RG: Islet beta-cell endoplasmic reticulum stress precedes the onset of type 1 diabetes in the nonobese diabetic mouse model. Diabetes 2012;61:818-827. 